\title{
NUMERICAL ANALYSIS IN TRIPLE TUBE HEAT EXCHANGER WITH FINS
}

\section{S. SUDHAKAR BABU ${ }^{1}$, *K. HANISH CHANDRA ${ }^{2}$ \& G. CHENNA MAHESH ${ }^{3}$}

${ }^{I}$ Associate Professor, Department of Mechanical Engineering, Koneru Lakshmaiah Education Foundation, Green Fields, Vaddeswaram, Guntur, Andhra Pradesh, 522502, India

${ }^{2}$ PG scholar, Department of Mechanical Engineering, Koneru Lakshmaiah Education Foundation, Green Fields, Vaddeswaram, Guntur, Andhra Pradesh, 522502, India

ABSTRACT
System in which heat transfer takes place is a heat exchanger. Current paper attempts heat transfer analysis in concentric
triple tube heat exchanger, with fins on the inner annulus. Material used for fins and tubes is steel, because it is a good
conductor of heat. Fins of different height are added and at different temperatures, analysis is carried out. fin heights
considered is $6 \mathrm{~mm} 8 \mathrm{~mm} 10 \mathrm{~mm}$, temperature range of 345K, 353K, 363K, temperatures at 345K is considered and values
calculated at fin height of $6 \mathrm{~mm}, 8 \mathrm{~mm}, 10 \mathrm{~mm}$. In same process temperatures for 353K and 363K is carried out for fin
heights of $6 \mathrm{~mm}, 8 \mathrm{~mm}, 10 \mathrm{~mm}$.
KEYWORDS: HX- Heat Exchanger, TTHX-Triple Tube Heat Exchanger, NF-Nano Fluids \& Corrugation Technique

Received: Feb 01, 2020; Accepted: Feb 14, 2020; Published: Mar 07, 2020; Paper Id.: IJMPERDAPR2020140

\section{INTRODUCTION}

Heat Exchangers are used to reduce the temperature of fluids in industries. Transfer of heat follows three methods

- conduction

- convection

- $\quad$ radiation

In a heat exchanger the biggest contribution is due to convection, Water \&oil act as major source. Double tube heat exchangers had been used in industries achieves better heat transfer efficiency. Triple tube heat exchangers are employed to reduce the disadvantages of double tube heat exchanger by increasing the area of flow which leads It increases the productivity per unit time, triple tube heat exchanger consists of 3 concentric tubes, inner tube, intermediate tube, outer tube, in TTHX different methods used one among them is the

- Corrugation technique (ridges and groves)

- Use of Nano -fluids have been implemented to get better result corrugation technique which deals with the implementation of the fins the heat transfer rate can be increased with the use of fins, and the other process is Nano fluids heat exchange takes place while the fluid is passed the heat transfer rate depend upon the various properties of fluids introducing Nano particles increases thermal conductivity important accept taken into consideration is the settlement and coagulation of Nano particles due to density. 


\section{LITERATURE REVIEW}

Abdalla Gomaa [1]

Abdalla Gomaa conducted work on triple tube HX with ribs, calculated the performance at different flow rates and at flow pattern and temperature variation and at different ribs heights, calculated at various Reynolds number he found that high values can be achieved at low values of Reynolds number, depending upon the height the better values can be obtained at low rib height and high rib pitch.

\section{Mehdi Bahiraei [2]}

Mehdi Bahiraei conducted experiment to find out the properties of Nano fluids for that he had used TTHX, conducted at various rib heights $(\mathrm{H}=3,6$ and $9 \mathrm{~mm})$ and different rib pitch $(\lambda=50,100$ and $150 \mathrm{~mm})$, ribbed triple tube heat exchanger is studied,Nano fluid used is Nano platelet graphene -platinum composite powder. The Nano fluid is passed through the inner annulus; he found that effective heat transfer is obtained at small rib pitch and higher rib height.

\section{G.A. Quadir [3]}

G.A. Quadir conducted experiment on TTHX with parallel flow, he conducted on two different flow cases Cold-HotNormal and other case as Normal-Hot-Cold, the fluid flow is parallel to each other, and he considered two phases, insulated and non-insulated, he found out that Normal-Hot-Cold is more effective than Cold-Hot-Normal.

Eda Feyza Akyürek[4]

Eda Feyza Akyürek conducted experimental with Nano fluids of different concentration and varying Reynolds number he prepared the Nano fluids of different concentration of 0.4-0.6-0.8-1.2 and Reynolds numbers ranging from 4,000 to 20,000,Nano fluid he considered id $\mathrm{Al}_{2} \mathrm{O}_{3}$-water, Nano fluid, at low values of Nano particle concentration there is no influence of pressure drop, the heat exchanger is wire coil concentric tube heat exchanger.

Y.Phanindra[5]

Y.Phanindra conducted experiment in TTHX with the help of hybrid Nano fluid the fluid he considered transformer oil and $0.1 \%$ of $\mathrm{A} 12 \mathrm{O} 3 / \mathrm{Cu}$ Nano particle he synthesized separately by two step method and then added to oil to form Nano fluid in this he considered the Nano particle size of $60 \mathrm{~nm}$, we can see that Nusselt number value increased by $10.34 \%$ for $\mathrm{Al}_{2} \mathrm{O}_{3} / \mathrm{Cu}$ Nano fluid.

\section{PROCEDURE}

Triple tube heat exchanger,the design of the triple heat exchanger is done with the help of Catia v5 software, it consists of 3 tubes- inner, intermediate and outer tubes, the dimensions of the tubes are $13.5 \mathrm{~mm}$ and $45 \mathrm{~mm}$ and $70 \mathrm{~mm}$ of radius and thickness of tube is $1.5 \mathrm{~mm}$,rectangular fins are employed on the inner tube with different heights $10 \mathrm{~mm}, 8 \mathrm{~mm}, 6 \mathrm{~mm}$. Cold fluid passed in the outer tube, normal fluid is passed through inner tube, hot fluid passed in the intermediate tube. The calculations are done for different temperatures the normal water taken as $291 \mathrm{k}$, hot water as $343 \mathrm{k}$, cold water as $283 \mathrm{k}$. Values are calculated for different fins heights the fin which has high heat transfer of hot water is again considered and calculated at different temperatures at $353 \mathrm{k}, 363 \mathrm{k}$. 


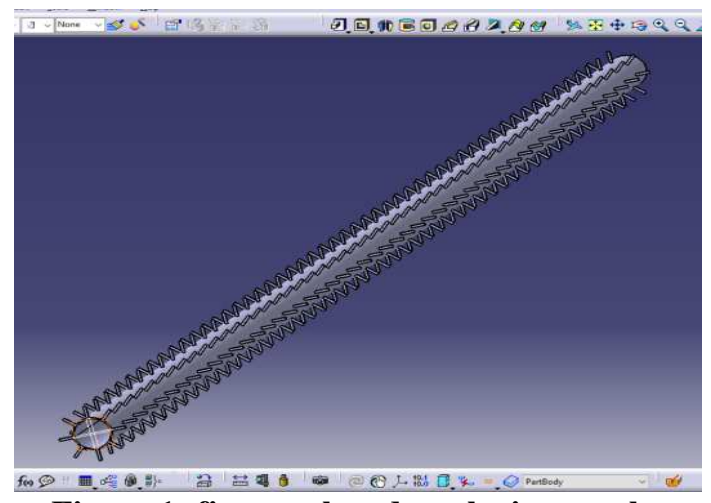

Figure 1: fins employed on the inner tube

Fins are used to increase surface area and the heat transfer increase, a series of fins are implanted on the surface total of 30 fins are employed on the surface with the fin of $2 \mathrm{~mm}$ of length and $1 \mathrm{~mm}$ of breath, heights vary with time for same temperature of $70 \mathrm{~K}$ of inlet temperature of hot fluid [6-8].

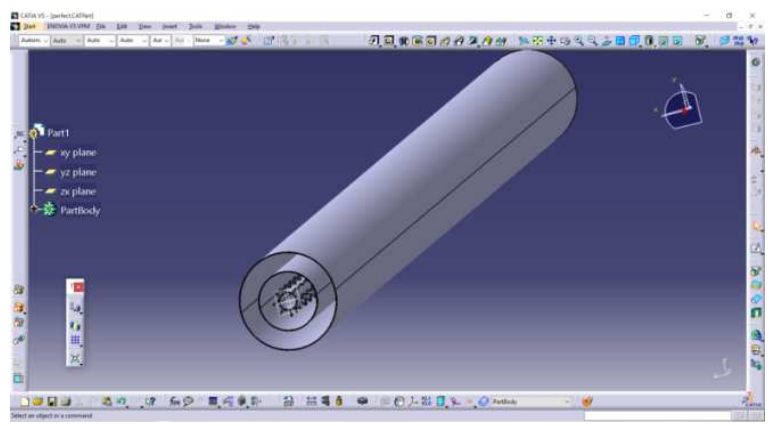

Figure 2: triple tube heat exchanger with inner fins

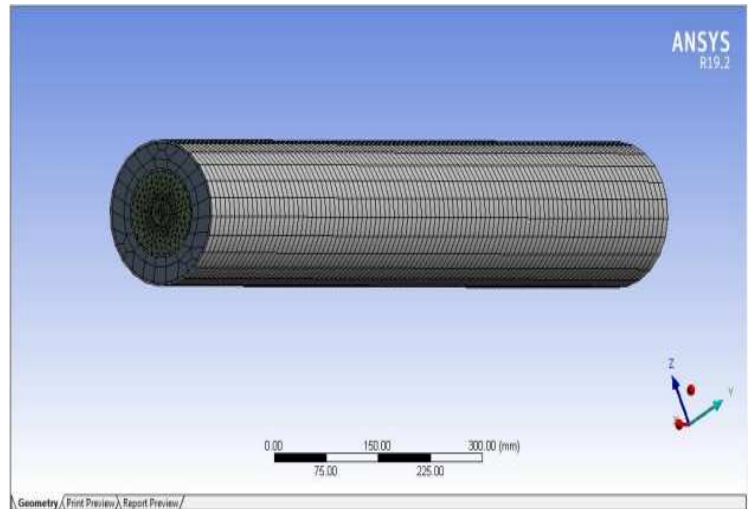

Figure 3: meshing

Meshing is process of dividing the whole component into different no of elements when temperature is applied on component distribute it uniformly. Sizing is given to the pipe and number of divisions is given 30 . 


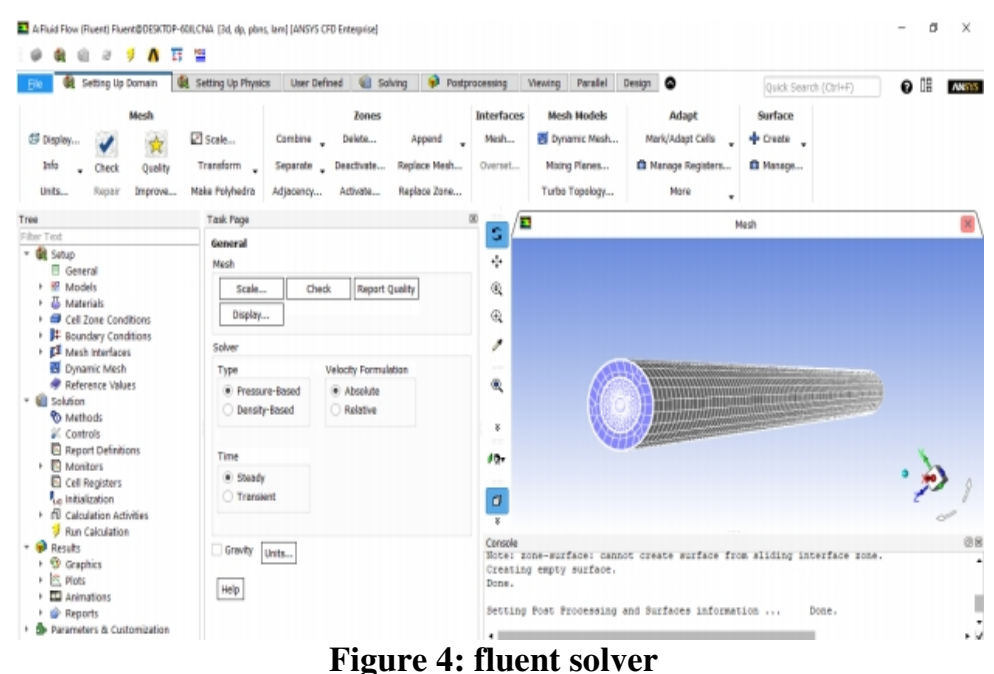

Figure 4: fluent solver

Fluent solver is used to run calculations for the tube heat exchanger. The energy is kept on the flow is laminar and the gravity is taken as negative 9.81, material used is steel for the pipes and Inlet values are given for inner pipe, intermediate and outer pipes, mass flow rate is taken as $0.10 \mathrm{~kg} / \mathrm{s}$ for inner tube and outer tube, $0.048 \mathrm{~kg} / \mathrm{s}$ for intermediate tube. The velocity is taken as $0.06 \mathrm{~m} / \mathrm{s}$, the values are calculated for 1000 iterations.

\section{RESULTS}

\section{Case 1}

$10 \mathrm{~mm}$ fin with the inlet temperatures considered as $291 \mathrm{k}$ in inner pipe, and $343 \mathrm{k}$ in intermediate pipe, and $283 \mathrm{k}$ in the outer pipe the results as follows

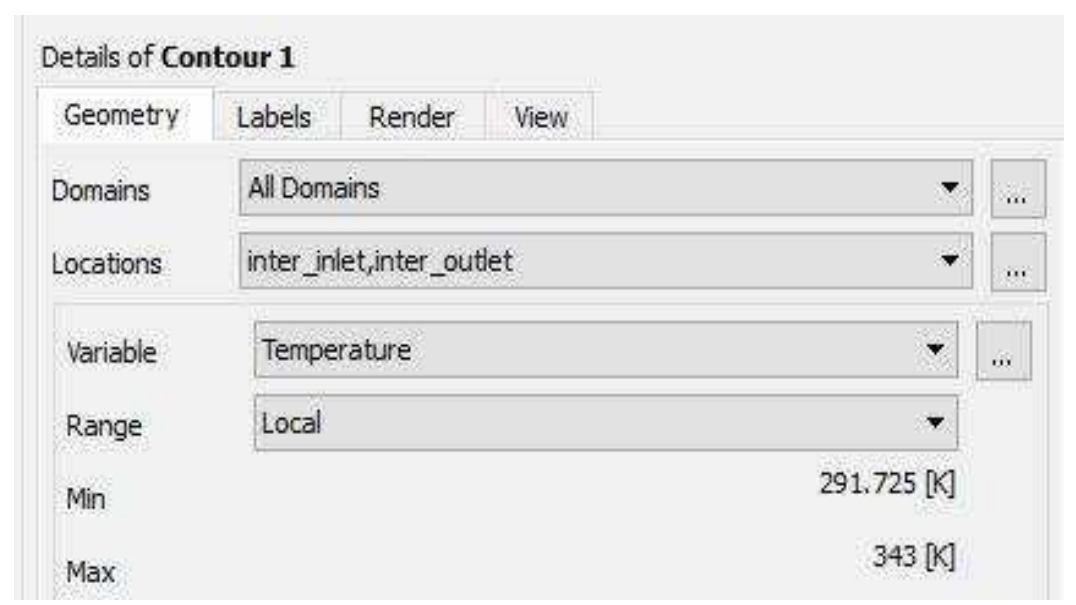

Figure 5: intermediate tube values for fin size $10 \mathrm{~mm}$

The decrease of temperature from $343 \mathrm{k}$ to $291.7 \mathrm{k}$ in the intermediate tube, and amount of increase $291 \mathrm{k}$ to 306 $\mathrm{k}$ in the inner tube, and the increase of temperature in the outer tube by $283 \mathrm{k}$ to $304 \mathrm{k}$

\begin{tabular}{|l|c|c|c|}
\hline \multicolumn{1}{|c|}{ Fin Size } & Inner & Intermediate & Outer \\
\hline Inlet & $291 \mathrm{k}$ & $343 \mathrm{k}$ & $283 \mathrm{k}$ \\
\hline Outlet & $306 \mathrm{k}$ & $291 \mathrm{k}$ & $304 \mathrm{k}$ \\
\hline
\end{tabular}




\section{Case 2}

$8 \mathrm{~mm}$ fin, with the inlet temperatures are considered as, $291 \mathrm{k}$ in inner pipe and $343 \mathrm{k}$ in intermediate pipe and, $283 \mathrm{k}$ in the outer pipe the results as follows.

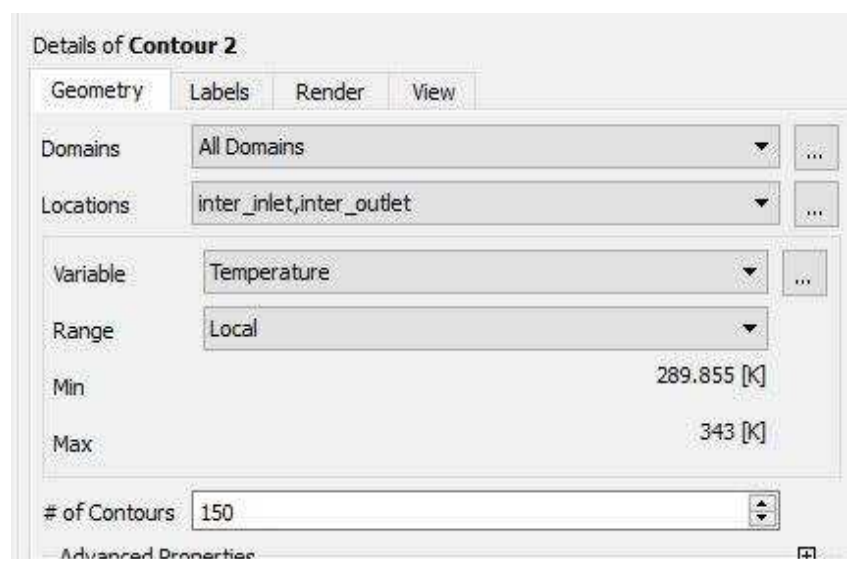

Figure 6: intermediate tube values for fin size $8 \mathrm{~mm}$

\begin{tabular}{|l|c|c|c|}
\hline \multicolumn{1}{|c|}{ Fin Size } & Inner & Intermediate & Outer \\
\hline Inlet & $291 \mathrm{k}$ & $343 \mathrm{k}$ & $283 \mathrm{k}$ \\
\hline Outlet & $307 \mathrm{k}$ & $289 \mathrm{k}$ & $314 \mathrm{k}$ \\
\hline
\end{tabular}

The heat transferred through the intermediate pipe is maximum with the use of the $8 \mathrm{~mm}$ fins decrease of $54 \mathrm{k}$, from $343 \mathrm{k}$ to $289 \mathrm{k}$ in intermediate tube, and increase in inner tube from $291 \mathrm{k}$ to $307.6 \mathrm{k}$, and increase in Outer tube from $283 \mathrm{k}$ to $314.7 \mathrm{k}$.

\section{Case 3}

$6 \mathrm{~mm}$ fin with inlet temperatures are considered as $291 \mathrm{~K}$ in inner pipe, and $343 \mathrm{~K}$ in intermediate pipe, and 283 in the outer pipe the results as follows.

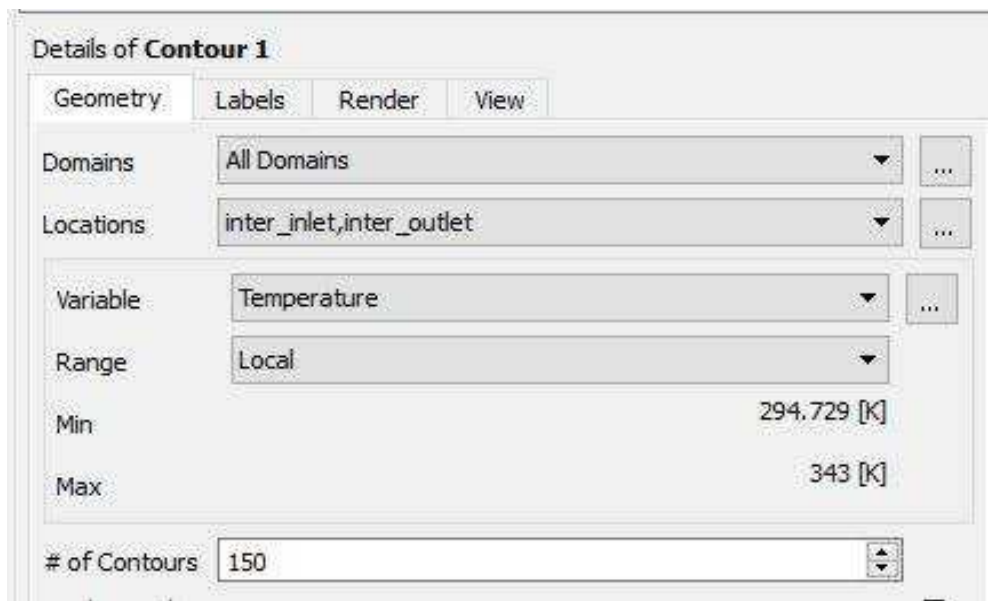

Figure 7: Intermediate tube values for fin size $6 \mathbf{~ m m}$

\begin{tabular}{|l|c|c|c|}
\hline \multicolumn{1}{|c|}{ Fin Size } & Inner & Intermediate & Outer \\
\hline Inlet & $291 \mathrm{k}$ & $343 \mathrm{k}$ & $283 \mathrm{k}$ \\
\hline Outlet & $312 \mathrm{k}$ & $294 \mathrm{k}$ & $306 \mathrm{k}$ \\
\hline
\end{tabular}

The decrease of temperature from $343 \mathrm{k}$ to $294 \mathrm{k}$ in the intermediate tube, and amount of increase $291 \mathrm{k}$ to $312 \mathrm{k}$ 
in the inner tube, and the increase of temperature in the outer tube by $283 \mathrm{k}$ to $306.4 \mathrm{k}$. Total temperature distribution of the tube heat exchanger with different fin size are given graphically

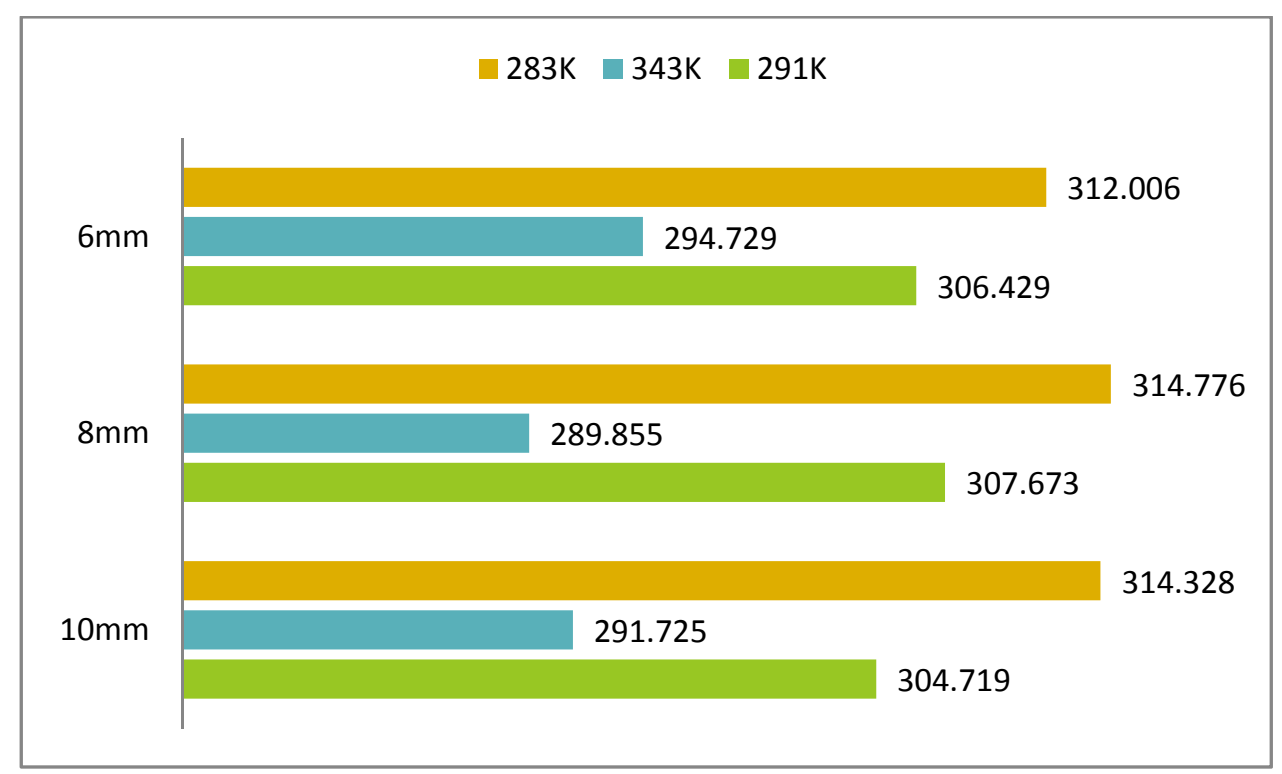

Figure 8: overall heat transfer distribution for temperature of 343k inlet.

\section{Case 4}

$8 \mathrm{~mm}$ is considered and the inlet temperatures are considered $353 \mathrm{~K}$ the reduction in temperature from $353 \mathrm{k}$ to $290 \mathrm{k}$

\begin{tabular}{|c|c|c|c|c|c|}
\hline Geometry & Labels & Render & View & & \\
\hline Domains & \multicolumn{3}{|c|}{ All Domains } & $\rightarrow$ & $\ldots$ \\
\hline Locations & \multicolumn{3}{|c|}{ inter_inlet,inter_outlet } & - & $\ldots$ \\
\hline Variable & \multicolumn{3}{|c|}{ Temperature } & - & $\ldots$ \\
\hline Range & \multicolumn{3}{|l|}{ Local } & $\rightarrow$ & \\
\hline Min & & & & \multicolumn{2}{|l|}{$290.974[K]$} \\
\hline Max & & & & \multicolumn{2}{|l|}{$353[K]$} \\
\hline \# of Contours & \multicolumn{3}{|l|}{150} & $\div$ & \\
\hline
\end{tabular}

The temperature change for $8 \mathrm{~mm}$ fin and temperature of $353 \mathrm{k}$ is reduced to $290.97 \mathrm{k}$ in the intermediate fin, and increase in inner tube from $291 \mathrm{k}$ to $306.7 \mathrm{~K}$, and increase in Outer tube from $283 \mathrm{k}$ to $320.7 \mathrm{k}$.

\section{Case 5}

\begin{tabular}{|l|c|c|c|}
\hline \multicolumn{1}{|c|}{ Fin Size } & Inner & Intermediate & Outer \\
\hline Inlet & $291 \mathrm{k}$ & $353 \mathrm{k}$ & $283 \mathrm{k}$ \\
\hline Outlet & $306 \mathrm{k}$ & $290 \mathrm{k}$ & $320 \mathrm{k}$ \\
\hline
\end{tabular}

The for the fin size $8 \mathrm{~mm}$ is considered and the inlet temperatures are considered $363 \mathrm{~K}$ 


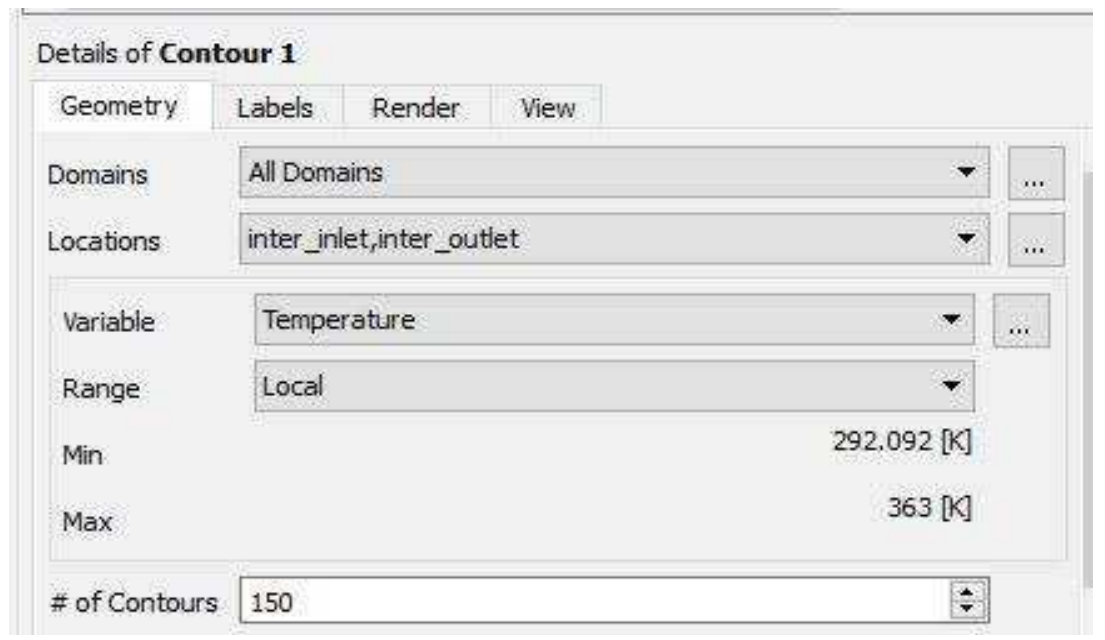

Figure 10: Intermediate tube values for temperature at $363 \mathrm{~K}$

The temperature change for $8 \mathrm{~mm}$ fin and temperature of $363 \mathrm{k}$ is reduced to $292.09 \mathrm{~K}$, and increase in inner tube from $291 \mathrm{~K}$ to $307.2 \mathrm{~K}$, and increase in Outer tube from $283 \mathrm{~K}$ to $316.7 \mathrm{~K}$.

\begin{tabular}{|l|c|c|c|}
\hline \multicolumn{1}{|c|}{ Fin Size } & Inner & Intermediate & Outer \\
\hline Inlet & $291 \mathrm{k}$ & $343 \mathrm{k}$ & $283 \mathrm{k}$ \\
\hline Outlet & $307 \mathrm{k}$ & $292 \mathrm{k}$ & $316 \mathrm{k}$ \\
\hline
\end{tabular}

\section{CONCLUSIONS}

Temperature variation along the triple tube heat exchanger with inserted fin is calculated with the hot fluid is flown through the intermediate tube. The heat transfer is calculated for fins of sizes $6 \mathrm{~mm}, 8 \mathrm{~mm}, 10 \mathrm{~mm}$. the temperature reduction is high with fin size $8 \mathrm{~mm}$. The maximum value of temperature can be reduced up to $290 \mathrm{~K}$, based on heat transfer the case with high rib length and small rib area is suggested.

\section{REFERENCES}

1. Abdalla Gomaa, M.A. Halim, Ashraf Mimi Elsaid, (2017), Enhancement of cooling characteristics and optimization of a triple concentric-tube heat exchanger with inserted ribs, International Journal of Thermal Sciences, 120, 106-120.

2. Mehdi Bahiraei, Nima Mazaheri, Ali Rizehvandi, (2019). Application of a hybrid nanofluid containing graphene nanoplateletplatinum composite powder in a triple-tube heat exchanger equipped with inserted ribs, Applied Thermal Engineering, 149, 588-601.

3. G.A. Quadir, Saqab S. Jarallah, N.J. Salman Ahmed, Irfan Anjum Badruddin, (2013). Experimental investigation of the performance of a triple concentric pipe heat exchanger, International Journal of Heat and Mass Transfer, 62, 562-566.

4. Vishwa Mohan Behera, D.H. Das, Ayusman Nayak, (2014), Numerical analysis of triple tube heat exchanger using ansys, International Journal of Scientific \& Engineering Research, 5(11), 1226-1231.

5. Y. Phanindra, S.D. Kumar, S. Pugazhendhi, (2018), Experimental Investigation on $\mathrm{Al}_{2} \mathrm{O}_{3} \& \mathrm{Cu} / \mathrm{Oil}$ Hybrid Nano fluid using Concentric Tube Heat Exchanger, Materials Today: Proceedings, 5(5), 12142-12150,

6. Metta, V.R., Konijeti, R., Dasore, A., Thermal design of spiral plate heat exchanger through numerical modelling, International Journal of Mechanical Engineering and Technology, 9(2018) 736-745. 
7. Ganna, S., Konijeti, R., Dasore, A., Comparative study of physical and chemical adsorbents with composite adsorbent pairs for application in adsorption refrigeration system, International Journal of Mechanical Engineering and Technology, 9(2018), $702-711$

8. Returi MC, Konijeti $R$ and Dasore A., 2019, "Heat transfer enhancement using hybrid nanofluids in spiral plate heat exchangers". Heat Transfer-Asian Res., 48, pp. 3128-3143. 